\title{
Thematic Development in English and Translated Academic Texts
}

\author{
Alireza Jalilifar \\ Shahid Chamran University of Ahvaz
}

\begin{abstract}
Thematic organization and thematic progression play crucial roles in the message function of language. An important question is how translators deal with these thematic choices as textual devices when a text is translated into another language. Few studies have unfortunately brought their significance into focus. The present study, therefore, investigates thematic development and progression in English academic texts and their translations in Persian. The corpus is selected from the first three pages of the first chapters of nine English applied linguistics books and their translation versions. These books are currently taught in the Iranian universities at undergraduate and graduate levels. Applying Halliday's (1994) thematic organization and McCabe's (1999) thematic progression, the study reveals significant differences in the original texts and their translations regarding thematic schemes. The study concludes that both authors and translators must be conscious of these tools in order to use them effectively and create more cohesive texts.
\end{abstract}

Keywords: theme; rheme; thematic organization; thematic progression; translation 


\section{Introduction}

An important aspect of functional grammar is the way information is structured in communication. If we are explaining something to another person, whether in speech or writing, we organize what we say in a way that will make it easier for the reader to understand. Theme and rheme are two terms which represent the way in which information is distributed in a message. Theme, as the point of departure (Halliday 1985), plays a major role in the organization, communication, comprehension, and interpretation of a message (Brown \& Yule 1983). The structuring of language as a message is realized in the thematic structure of the consistuent clauses of a text. This study, particularly, addresses theme and thematic patterns within and across sentences in original and translated texts leaving out the rheme section as it might be regarded less important in consideration of information structure of text.

Thematic patterning plays crucial roles in converting meaning from source language into target language. Making any unmotivated and unreasonable change into these textual structures may cause difficulties in conveying intended meaning(s) of source text's author, and so readers of translated texts might misinterpret the source text author as a result of changes made by the translator in the distribution of information in the translation. In the same line of argumentation, Ventola (1995), in comparing thematic structures of German philosophy texts and their parallel texts in English, attests to the fact that the translation choices that the translator has made do not follow and display the same rhetorical principles and effects as the author's original text. The translator changes the thematic structure of the clauses. Consequently, the translator will succeed, to some extent, in displaying the unfolding of the global structure of the text in the translated version.

From the readers' perspective, Ventola (1995) also adds that sometimes readers may find texts fuzzy since they consider some 
odd thematic structures that are not typical of the target language. The fault in these texts is very often placed on the author's failure of argumentation and rhetorical skills; it is presumed that the author's logic is inappropriate and his/her argumentation and rhetorics are seen to fail. But often the original argumentation is clear and wellstructured rhetorically in the source text; it is the translation that fails and distorts the argumentative and rhetorical patterns.

Thematic structure and progression may be quite different in various languages. Baker (1992, as cited in Munday 2001: 97) emphasizes that density and progression of cohesive ties play an important role throughout a text. This web of relationships might differ between source text and target text because of the different networks of lexical cohesion across languages.

Matthiessen (2004) argues that in Japanese, as in Tagalog, interpersonal theme is realized positionally by initial position; and the same is true about textual themes. Japanese, in contrast to Tagalog, tends to place topical theme early in the clause, after textual and interpersonal themes, but in line with Tagalog, Japanese may mark topical themes segmentally by a "postposition" such as $w a$ or mo (550). Similarly, Ventola (1995) concludes that there is no question about the usefulness of the analytical devices -thematic structures- for applied linguistics, but these tools are not expected to function in the same way in various languages. Contrastive linguistics has paid some attention to these differences (Ghadessy 1999; Martinez 2003; Raveli 2004; Ventola 1995), but an area that is relatively less explored is what happens to the text thematic organization and progression when it goes through a translation process.

Williams (2005) analyzed thematic items referring to research and researchers in the discussion section of Spanish biomedical articles and English-Spanish translation. The corpus used in his study contained approximately half a million words and consisted of 192 research articles with Introduction, Method, Result, and Discussion (IMRD) format. The results showed that the Spanish texts had more 
integral references and more general researcher nouns in their themes whereas the translations had more singular research nouns associated with more propositional adjuncts in the Spanish texts but with more subject themes in the translations.

Zhou (2006) applied the theme construction to Chinese language showing some grammatical dissimilarity with English. She worked on interpersonal metafunction and attempted to show whether advertisement texts in Chinese and English journals engender similarities in interpersonal metafunction. Results showed that the modal themes were not prevalent across both corpora, and so the advertisement texts did not engender similarities in interpersonal metafunction across two languages.

Since attention to thematic structures is an important issue in translating and getting the meaning across and specifically work on translation of academic texts is still scarce, this study aims to investigate the possible variations that may happen in the thematic structures of academic texts when they are translated. The result of this study is expected to reveal crucial points and offer important hints to translators in relation to the function of theme in scientific texts and also help readers to better comprehend translated texts. In general, the motivation behind the present research is to see whether there is any significant difference between English applied linguistics books and their Persian translations regarding their thematic organization and progression.

\section{Methodology}

\subsection{Text Selection}

The corpus used in this study was selected from the first three pages of the first chapters of eighteen applied linguistics books (nine in English and nine in Persian). The selection was done with the aim 
of building a corpus representative of applied linguistics books taught in Iranian universities at undergraduate and graduate levels and translated into Persian. The rationale for focus on the first chapter was four folds: First, the first chapter of a book is usually its point of departure. Second, it also allowed the researcher to maintain consistency of thematic progression among paragraphs in each text and avoid invalid judgment of thematicity. Third, the texts represented a variety of authors and translators to minimize the influence of individual preferences in translation, and last, it appeared that this quantity was enough to allow the researcher to arrive at valid generalizations. The corpus was divided into two subcorpora: sample academic texts in English and sample academic texts in Persian. The Persian texts were the translated versions of the same English texts. The obtained corpus contained 24,110 words (11,664 for English and 12,446 for Persian).

\subsection{Instruments}

Halliday (1994: 53) categorized the elements which occur in initial position of the clause into three types, mirroring Halliday's (1994) three major metafunctions of language, in view of Ping (2003):

First is the ideational (topical or experiential) theme consisting of anything that represents a process, a participant in a process, and circumstances associated with that process. These elements function as predicator, subject, and complement or adjunct, but as predicator is rarely thematic. Topical theme is presented by a nominal group (e.g., everyone), a prepositional phrase (e.g., with ships continually at sea), or an adverbial group (e.g., by the middle of $15^{\text {th }}$ century). Ping (2003: 3) pin-points that the topical theme, as the most important theme type, comprises only one experiential element and ends the thematic unit of the clause. Halliday (1994: 53) also claims that "any clause without this constituent lacks an anchorage in the 
realm of experience."

Second, the interpersonal theme consists of any combination of vocatives (direct addresses such as personal names), modal adjuncts, and mood marking elements. A vocative is any element that may come more or less anywhere in the clause. It is thematic if it precedes the topical theme. Modal adjunct occurs preceding the topical theme. And finally, a mood marking item is a finite verbal operator-temporal and modal- if it precedes the topical theme; or a WH-interrogative and imperative let's, if it is not preceded by another experiential element.

Third, the textual theme includes continuatives (small set of discourse items which signal that a new move is beginning such as yes, no, oh...), structural elements (coordinates and subordinates), and conjunctive adjuncts which relate the clause to the preceding texts and occur preceding the topical theme (e.g., in other words).

Another categorization used in this study was Halliday's (1994: 44) distinction between marked and unmarked theme. The rationale for the division is that there is a default option in presenting information in a clause. Unmarked theme is the subject of the clause, the most usual form being nominalization. For example,

(1) Language learning is not a set of easy step that can be programmed in a quick do-it-yourself kit. (Brown 2000: 1)

Marked theme is other than the subject of the clause, the most usual form being adverbial or prepositional groups. For example,

(2) Each day, we encounter sentences we have never seen or heard before. (Falk 1978: 4)

Since theme may form one or more than one consistuent in the structure of clause, Halliday (1994: 54) also introduced simple and multiple themes according to their internal structure. Simple themes always have a topical element with no further internal structure and 
the thematic item itself is a single element that is always topical. Multiple themes may have the interpersonal and textual themes in addition to topical themes and have a further internal structure of their own. The ideational theme is always the final one and anything that follows the first ideational element of the clause is automatically part of the rheme. For example,

(3) Similarly, we speak and comprehend sentences with little or no awareness of the mental and physical processes involved in language. (Falk 1978: 4)

Another general model was the revised Danes' (1974, as cited in Downing, 2001) model of TP patterns and used for determining thematic progression. The practical frameworks to analyze the data were those proposed by McCabe (1999) and North (2005). Danes (1974, as cited in Downing 2001: 5) proposed linear TP, constant TP, split rheme, and split theme progression. Linear TP is a basic thematic progression pattern, where the item in the rheme of the first clause becomes the theme of the subsequent clause. For example,

(4) At this point we must add an important qualification to what we have just said. That is, we are using the terms rule and rule-governed in the special way that linguists use them. This usage is very different from the layperson's understanding of the terms. (Akmajian 1995: 7)

In constant $\mathrm{TP}$, the item in the theme of the first clause is also selected as the theme of the following clause, though not necessarily with identical wording. For example,

(5) And yet we understand them and don't even notice that they are new. We speak, but usually we are not aware of the movements of our tongue, lips, or other parts of the 
88 Thematic Development in English and Translated Academic Texts

mouth or throat involved in the production of sounds. (Falk 1978: 4)

In split rhematic progression, the rheme of the first clause is split into two items, each in turn being taken as a theme element in subsequent clauses. For example,

(6) I will use the term 'language teaching method' to mean a coherent set of links between actions and thoughts in language teaching. The actions are the techniques and the thoughts are the principles in the title of this book: Techniques and Principles in Language Teaching. (Freeman 2000: 1)

To Danes' thematic progression patterns, McCabe (1999) adds split rheme progression in which the theme of the first clause is split into two or more ideas, and these ideas are developed in the themes of subsequent clauses.

Adopting Danes' thematic progression patterns, McCabe (1999) proposed a revised model. She catagorized these patterns into (a) theme progression including constant theme and split theme and (b) rheme progression including simple linear and split rheme. McCabe (1999) did not consider derived theme as a different sort of TP, since it may be related to proceeding themes and rhemes through some types of inference involved in simple linear or constant theme. According to McCabe (1999), there are a rather large percentage of clauses which do not fit into any of the TP patterns proposed by Danes, since it appears that Danes employed a standard for theme specification which accords more with the notion of given. As argued by Martinez (2003), these practical, reliable, and up-to-date models provide plausible and attestable mechanisms for determining the thematic structures of the texts correctly. Thus, most of the studies that have been done in terms of thematic analysis have resorted to these two models. 


\subsection{Procedure}

The English texts and their Persian translations were analyzed according to the above mentioned models to determine their thematic organization and progression and to examine the similarities and differences that would exist in English and Persian texts in terms of thematicity. Following McCabe (1999), in order to make the analysis possible, the researcher adopted T-unit or "independent conjoinable clause complex" as the unit of analysis since, as McCabe (1999: 73) mentions, it is recognized as optimal unit for textual analysis regarding thematic progression. North (2005: 139) contends that one of the major problems related to the coordinated independent clauses is ellipsis. Following the procedure of North (2005), in this study, the coordinated clauses in which the subjects were ellipted were considered as separated units provided that the clause still included a finite element.

One problem with textual analysis is that there is always the danger of misinterpretation. To minimize the threat of reliability in the analysis, the first three pages of two applied linguistics books in both languages from the corpus were also analyzed by an experienced researcher in applied linguistics and agreement was made on the method of analysis.

\section{Data Analysis}

To analyze the texts quantitatively, the frequency of different theme types as well as patterns of thematic progression was calculated. Next, Chi-square test was employed to compare and contrast the obtained frequencies to see the statistically significant differences. In sum, the data were analyzed using the statistics software SPSS (Statistics Package for Social Sciences). 
90 Thematic Development in English and Translated Academic Texts

\subsection{Theme types}

The data presented in the following table shows the total frequency and percentage of different types of theme in English and Persian academic texts.

The total number and percentage of textual themes in Persian texts were about twice the themes in English texts alluding to the more argumentative, impersonal, and objective nature of Persian texts, contrary to McCabe's (1999) results. She revealed the identically total number of textual themes in her corpus of English and Spanish history texts.

Table 1. Theme Types in English and Persian Texts

\begin{tabular}{ccc}
\hline & English & Persian \\
\hline Textual & F (\%) & F (\%) \\
\hline Interpersonal & $27(19.44)$ & $222(34.52)$ \\
Simple & $455(78.31)$ & $40(6.22)$ \\
Multiple & $126(21.68)$ & $419(65.16)$ \\
Marked & $229(39.41)$ & $224(34.83)$ \\
Unmarked & $352(60.58)$ & $350(54.43)$ \\
\hline
\end{tabular}

She found 23.40\% textual theme in English and 23.91\% in Spanish texts. The frequency and percentage of different sorts of textual theme were also clarified and compared in both English and Persian languages.

Obviously, in both text types, coordinators were more prevalent as theme than conjunctive adjuncts, given that their position in the Tunit was obligatorily more initial (See Table 2). Ghadessy (1995) asserts that in most texts, there are plenty of conjunctions functioning as textual themes. In all, the greater frequency of textual theme types (conjunctions and conjunctives) might imply that Persian, at least in the present study, prefers a variety of conjunctions which function as explicit markers of the semantic relations (addition, contrast,...) between 
sentences and paragraphs in texts. This result, in some aspects, is, and in some other aspects, is not similar to McCabe's (1999) findings. She concluded that in Spanish more conjunctive adjuncts were used in theme position than in English, while in English more coordinators were used. So, the result of this study in terms of different kinds of textual theme is in line with McCabe's (1999) findings since she revealed that the number of conjunctive adjuncts in English compared with Spanish was low, and is in contrast with McCabe's (1999) results since in her study, coordinated conjunctions in English occurred in a higher proportion than in Spanish.

Continuatives were not utilized in any text type, similar to McCabe's (1999) findings in which only two instances of continuatives were found in the Spanish corpus. According to Halliday (1994: 53), continuatives signal a new move beginning or a move to the next point in the dialog is taking place. Thus, continuatives are generally tokens of spoken discourse rather than written discourse.

Table 2. Textual Themes in English and Persian Texts

\begin{tabular}{cccc}
\hline & English & Persian & \\
\hline & $\mathrm{F}(\%)$ & $\mathrm{F}(\%)$ & Total \\
\hline Conjunction & $77(13.25)$ & $167(25.97)$ & 244 \\
Conjunctive & $36(6.19)$ & $55(8.55)$ & 91 \\
Continuative & 0 & 0 & 0 \\
\hline Total & 113 & 222 & 335
\end{tabular}

The two languages (both academic text types) were also analyzed concerning the frequency of interpersonal themes, and a relative similarity was found across English texts and their translated versions.

The most frequent type of interpersonal themes was modal adjuncts in Persian texts and finite verbal operators in English texts. Systemic functional accounts of theme (Bloor \& Bloor 1995; Halliday 1994) all include modal theme as a category of interpersonal theme. Modal meanings have several different realizations in the clause. As McCabe 
(1999: 229) states, the main types of realization are modal adjuncts and finite operators. For Halliday (1994: 49), modal adjuncts "express the speaker's judgment regarding the relevance of the message." An interesting point is that though the number of interpersonal themes was very low, their varieties were high across both text types. McCabe (1999) also found relative similarity in the infrequent use of modal adjuncts across Spanish and English. She found only 39 cases or $2.67 \%$ and 40 cases or $3.09 \%$ of modal adjuncts in English and Spanish texts respectively. Finite verbal operators, though not incorporated in translated texts, showed no significant difference between the two text types.

Table 3. Interpersonal Themes in English and Persian Texts

\begin{tabular}{cccc}
\hline & English & Persian & \\
\hline & $\mathrm{F}(\%)$ & $\mathrm{F}(\%)$ & Total \\
\hline Modal & $16(2.75)$ & $39(6.06)$ & 55 \\
Finite & $11(1.89)$ & $1(0.15)$ & 12 \\
Let's & 0 & 0 & 0 \\
\hline Total & 27 & 40 & 67
\end{tabular}

Although the percentage of marked topical themes was somewhat similar in both languages, the frequency of non-subject topical themes in Persian was higher. 229 cases or 39.41\% (in English) and 293 cases or $45.56 \%$ (in Persian) of the total topical themes were marked (See Table 1). Whittaker (1995) and Martinez's (2003) relate this greater inclusion of marked theme to the argumentative nature of paragraphs in which this type of theme is used. 52 cases $(8.08 \%)$ and 49 cases $(8.43 \%)$ of all marked themes in Persian and English texts were clause as themes respectively.

Unmarked themes were somewhat similar in frequency across both text types. Participant theme was the most frequent in both source and translated texts. Despite marked similarity, the greater proportion 
of participant theme in translated texts might reflect the different tendencies in both languages towards active/passive construction. Other types of unmarked theme were either rarely used, or not utilized in the data at all. The number of WH themes in both text types was very low, though more frequent in English texts. There were a few cases of extraposition and existential themes in English texts whereas no such patterns occurred in Persian texts. Whittaker (1995) and Ghadessy (1999) put into perspective cases of extraposition where it appears in the subject position followed by a finite verbal operator (especially to be) and an adjective which indicates the writer's judgment as interpersonal theme. Note the following example:

(7) T-unit 1: It is important to recognize that_methods link thoughts and actions because teaching is not entirely about one or the other. (Freeman 2000: 1)

But in this study, this structure was not considered as interpersonal theme since, following McCabe (1999), the clause which follows the it clause is an embedded one. So if the it clause is considered as interpersonal theme, then there is no rheme in the clause complex at all. Furthermore, the expression of modality appears in the neutral point of the clause neither in the theme, nor in the rheme. Following Halliday (1994), if it was the first element, so it was considered as the theme of the clause.

Table 4. Unmarked Themes in English and Persian Texts

\begin{tabular}{cccc}
\hline & English & Persian & \\
\hline & $\mathrm{F}(\%)$ & $\mathrm{F}(\%)$ & Total \\
\hline Participant & $297(51.11)$ & $336(52.25)$ & 633 \\
Wh & $25(4.30)$ & $14(2.17)$ & 39 \\
Extraposition & $21(3.61)$ & 0 & 21 \\
Existential & $9(1.54)$ & 0 & 9 \\
\hline Total & 352 & 350 & 702
\end{tabular}


94 Thematic Development in English and Translated Academic Texts

Simple themes were somewhat identical in both corpora, though more frequent in English. Majority of simple themes were unmarked (286 cases or $49.22 \%$ in English and 247 cases or $38.41 \%$ in Persian). Multiple themes in the translated texts were used to a greater extent than in English (See Table 5). The most frequent type of multiple themes in both text types was textual $\wedge$ topical. Though used frequently in both corpora, this pattern was more frequent in Persian. Also, 18 cases or $9.78 \%$ from textual $\wedge$ topical multiple themes in Persian and 4 cases or $4.04 \%$ from the same pattern in English contained more than one textual theme (e.g., textual ${ }^{\wedge}$ textual ${ }^{\wedge}$ topical, or textual $\wedge^{\wedge}$ textual $\wedge$ textual $\wedge$ topical). Note the following example:

(8) T-unit 14: And indeed the entire field of physics is an attempt to answer them. (Akmajian 1995: 5)

(9) T-unit 10: Vali ba vojode in, hanooz az besyari az lahaz dar šoroe fahme mahyate pičide in janbe az zendegie ensan gharar darim. (Bahrami 2003)

(But, however, still, from different aspects in understanding the nature of ...)

To compare frequencies of different types of theme in Persian and English texts chi-square test was applied. The results are displayed in the following table where $\boldsymbol{X} \mathbf{2}$ stands for the chi-square amounts, $\boldsymbol{d} \boldsymbol{f}$ stands for the degree of freedom, and $\boldsymbol{P}$ stands for the level of significance.

Table 5. Multiple Themes in English and Persian Texts

\begin{tabular}{|c|c|c|c|}
\hline & English & Persian & \\
\hline & $\mathrm{F}(\%)$ & $\mathrm{F}(\%)$ & Total \\
\hline $\mathrm{Textual}^{\wedge}$ topical & 99 (78.57) & $184(82.14)$ & 283 \\
\hline Inter $\wedge$ topical & $17(13.49)$ & $22(9.82)$ & 39 \\
\hline Textual $^{\wedge}$ inter $\wedge$ & $9(7.14)$ & $16(7.14)$ & 25 \\
\hline Inter $^{\wedge}$ textual ${ }^{\wedge}$ & $1(0.79)$ & $2(0.89)$ & 3 \\
\hline Total & 126 & 224 & 350 \\
\hline
\end{tabular}


Table 6. Chi-Square Analysis of Theme Types in Both Text Types

\begin{tabular}{cccccc}
\hline Theme types & Total themes & $\mathbf{( \% )}$ & X2 & df & P \\
\hline Textual in Persian & 222 & 34.52 & & & \\
Textual in English & 113 & 19.44 & 35.466 & 1 & 0.000 \\
Inter in Persian & 40 & 6.22 & & & \\
Inter in English & 27 & 4.64 & 2.522 & 1 & 0.112 \\
Simple in Persian & 419 & 65.16 & & & \\
Simple in English & 455 & 78.31 & 1.483 & 1 & 0.223 \\
Multiple in Persian & 224 & 34.83 & & & \\
Multiple in English & 126 & 21.68 & 27.440 & 1 & 0.000 \\
Marked in Persian & 293 & 45.56 & & & \\
Marked in English & 229 & 39.41 & 7.847 & 1 & 0.005 \\
Unmarked in Persian & 350 & 54.43 & & & \\
Unmarked in English & 352 & 60.58 & 0.006 & 1 & 0.940 \\
\hline X2=3.48 & & & & &
\end{tabular}

Differences were meaningful in textual, multiple, and marked themes. In other words, there were significant thematic differences between the English texts and Persian translations. These differences will be discussed later in detail.

\subsection{Thematic progression patterns}

All T-units in the corpus were analyzed to scrutinize the different types of thematic progression patterns including linear, constant, split rheme, and split theme. According to McCabe (1999: 176), the relationships are determined by focusing on the presence of different cohesive devices such as repetition, synonymy, antonym, hyponymy, pronouns, substitutions, ellipsis, and paraphrasing. This study followed North's (2005) procedure to identify links by looking for the first most constituent that has a topical link with the proceeding main clause. If the left most item identified as a link was a modifier then 
96 Thematic Development in English and Translated Academic Texts

the whole constituent was examined for link to preceding text.

In the present study, verb-initial structures with ellipsis were analyzed and put into simple linear progression chain. According to North (2005), these constructions have come from the previous rhemes, so they have linear progression provided that the subject for the verb is the same and the verbs have the same inflection for the tense. For example,

(10) T-unit 28: Chapter 9, "Pragmatics", explores some of the issues involved in describing human communication,

(11) T-unit 29: and proposes certain communication strategies that people use when they talk to each other. (Akmajian 1995: 6)

Moreover, following McCabe (1999), the themes for which the reader has to go back more than three clauses to find previously mentioned concept were not realized as part of thematic progression patterns. Finally, some themes which could not chain to previous themes or rhemes due to their grammatical nature could not be analyzed in terms of thematic progression patterns in both text types, and they fell into a separate group namely peripheral themes. The corpus was analyzed to determine the frequency of different types of thematic progression patterns (See Table 7).

Table 7. Frequency Analysis of Thematic Progression Patterns in English and Persian Texts

\begin{tabular}{lcccc}
\hline Linear (\%) & $\begin{array}{c}\text { Constant } \\
(\%)\end{array}$ & $\begin{array}{c}\text { Split rheme Split theme } \\
(\%)\end{array}$ & $(\%)$ & $\begin{array}{c}\text { Peripheral } \\
(\%)\end{array}$ \\
\hline English 236 (40.61) & $109(18.76)$ & $2(0.34)$ & 0 & $234(40.27)$ \\
Persian 359 (55.83) & $55(8.55)$ & $2(0.31)$ & 0 & $227(35.30)$ \\
\hline
\end{tabular}

Split theme was not utilized in any corpora and, even also, split 
rheme was very infrequent in English and Persian. But despite their higher proportion in translated texts, both authors and translators preferred to use linear over constant patterns. Similarly, McCabe's (1999) found more linear over constant chains relating this to the analytical or explicit nature of history texts, which was due to the pedagogical goal of the texts and asymmetric links between the writer and the reader. Table 7 also shows that the English corpus consistently evinced a higher percentage of clauses involved in constant theme progression chains than did the Persian corpus. Peripheral or miscellaneous themes were also close in number to linear chains, especially in English texts. To compare the total frequency of thematic progression patterns in both languages, the chi-square analysis was applied (See Table 8). Results indicated significant differences between both corpora in terms of thematic bonds.

Table 8. Chi-Square Analysis of Thematic Progression Patterns in English and Persian Texts

\begin{tabular}{cccccc}
\hline & Total TP & $(\%)$ & X2 & Df & P \\
\hline English & 347 & 59.72 & & & \\
Persian & 416 & 64.69 & 37.272 & 2 & 0.000 \\
\hline$X=5.99$ & & & & &
\end{tabular}

\section{Discussion and conclusion}

Analysis of the data made clear a number of appreciable points dealing with the research focus in terms of the different theme types and thematic progression patterns which are discussed below in tandem.

\subsection{Theme Types}

The results showed that different types of theme were employed 
in both original and translated texts. The percentage of these theme types was somewhat similar in both corpora. These similarities can be explained in terms of genre. According to Halliday and Hassan (1985: 46), texts belonging to the same genre represent a similar contextual configuration, that is, they show common characteristics in terms of field, tenor, and mode of discourse. Tenor of discourse involved in creating text can predict interpersonal meaning. Field of discourse recognized in the culture can predict the experiential meaning, and mode of discourse can predict textual meaning. So, similarities in field, tenor, and mode engender similarities in textual choices and are reflected in the thematic choices preferred since the field, tenor, and mode can be realized in topical, interpersonal, and textual themes respectively. Therefore, theme as one of the textual choices provides interesting insight into establishing similarities within and between genres.

McCabe (1999) mentions that textual themes are links which specify the relationship of the clause to the surrounding text and context. There is agreement among researchers that high frequency of textual (also marked, and multiple) themes in academic texts amounts to the argumentative nature of the texts which, according to McCabe (1999), contributes to greater coherence and cohesion. However, the overuse of textual themes in translated texts can be attributed to the place of textual themes in clauses in Persian. In English texts, at least in this study, textual themes were in rheme not in theme position, but in Persian in about all cases textual themes were in theme position. In other words, textual themes may occur anywhere in the clause in English but in Persian, they are obligatorily more initial, which is a natural tendency in Persian.

In most Persian translations, translators added textual themes to topical themes in the beginning of T-units that had no textual theme of their own in original versions. Note the following example: 
(12) Original text: T-unit 43: [Typical sentences] [were: theme rheme

"Thou hast a book. The house is beautiful. He has a kind dog. We have bread....] (Richards \& Rogers 2001: 5)

Translation: [Baraye mesal], [jomalate maamool] [be in textual topical rheme

sorat bodand:]

"Thou hast a book. The house is beautiful. He has a kind dog. We have bread.... (Bahrami 2005: 5)

Sometimes, in original texts, there were two or more successively separated sentences that were merged and related to each other by adding textual themes between them in translated texts, as in the following example:

(13) Original text: T-units $2 \& 3$ : [The times] [were changing.]

\section{theme 2 rheme2}

[The dominant role of religion in society] [was diminishing.]

theme 3

rheme 3

(Chastain 1988: 2)

Translation: [Dowreha] [dar hale taaghirand] [va naghše theme 2 rheme 2 textual theme 3

mosalate [asare xod ra az dast midahad]

rheme 3

(Noormohammadi 1999: 3)

In addition, even those textual themes that were in rheme position in English texts were fronted in translated texts. 
100 Thematic Development in English and Translated Academic Texts

(14) Original text: T-unit 50: [We] [can then undertake the theme

rheme

task of fitting the pieces together into a "paradigm"- an interlocking design, a theory of second language acquisition.] (Brown 2000: 4)

Translation: [Sepas] [ma] [mitavanim be hamahang textual topical rheme

kardane in ghetaat ba yekdigar be sorate sorathaye sarfi, tarhhaye mortabet zanjirehi va teorie faragirie zabane dovom bepardazim.] (Fahim 2002: 4)

(15) Original text: T-unit 6: [To say there is a coherence among theme

the links] [does not mean, however, that the techniques rheme

of one method cannot be used with another]. (Freeman 2000: 3)

Translation: [Ba vojode in,] [ensejame beine ertebatat] textual topical

[be maanaye an nist ke fonoone yek raveš nemitavanad rheme

ba raveši digar be kar gerefte šavad.] (Fahim \& Haqqani 2005: 3)

Doing so may result in developing more cohesive texts. Since clauses containing textual theme are related to preceding clauses and 
persuade the reader to follow the text.

Halliday (1994: 49-50) states that conjunctions are items which relate the clause to a preceding clause in the same sentence or the same clause complex while conjunctive adjuncts are those which relate the clause to the preceding text only. Conjunctions are similar in meaning to conjunctive adjuncts but they differ in that, while conjunctive adjuncts set up a semantic relationship with what precedes, conjunctions set up a relationship which is semantic and grammatical simultaneously. Conjunctions construct the two parts into a single unit. So, it seems that conjunctions are far more important in comprehending and creating cohesive texts. The results showed that conjunctions or structural elements and also conjunctive adjuncts were used more frequently in translated texts over original texts. The over-use of conjunctions in both corpora can be attributed to the place of conjunctions and conjunctive adjuncts in the clause. Since, as Halliday (1994) states, conjunctive adjuncts are not necessarily thematic, they may occur elsewhere in the clause whereas conjunctions are obligatory initial. However, it seems irrational to claim that the original texts in English suffered from tenure cohesion. Thematic structure and thematic progression are language specific. If so, we might expect different patterns of thematic progression to emerge in English texts.

In addition to the factual nature of both corpora, though more in Persian, the low percentage of interpersonal themes might reflect the shortage of well-balanced relationships between reader and writer in each text type. In the same line of argumentation, McCabe (1999) asserts that the writer wants to share information with the reader, and thus he is not attempting to persuade the reader to agree with his statements, since the bulk of his statements is factual. The greater frequency of interpersonal themes in Persian translations might result from the large number of T-units in Persian over English not the greater tendency of translators towards utilizing interpersonal themes in translation. 
Simple themes, being more frequent in both corpora, are giving continuity and cohesion to the texts. Multiple themes containing interpersonal themes were used infrequently in the two text types. This infrequency might reflect the factual and impersonal tone of the texts. Over-use of multiple themes, mostly containing textual themes in Persian texts might manifest the greater disposition of translators in applying textual themes reflecting linguistic tendencies in Persian rather than argumentative nature of the texts.

Though more frequent in English, unmarked themes were used frequently in both corpora. That is, both authors and translators apply themes that conflate with subjects of clauses. According to Halliday (1994), unmarked theme is used in the text if there is no prior context leading up to it, and no positive reasons for choosing anything else. Unmarked themes also give continuity to the texts and maintain coherence between sentences. In other words, the theme or rheme of the previous T-unit is used in the thematic position of the next clause and this connects the T-units together.

The existential theme, rarely used in English, did not occur in Persian at all. Lirola (2002) argues that existential theme underlines important or new information and shows the existence or nonexistence of an object or phenomenon. Over-use of existential theme can detract from the smooth development of the text and flow of information because it cannot establish a cohesive link or enter into the thematic progression. According to Martin (1992 as cited in McCabe 1999), existential clauses are ideally designed for introducing participants as unmarked new at the end of the clause. Thus, what is thematic here is the existence of some new participant in the discourse, and this thematization is confined to there. Also, McCabe (1999: 81) argues that existential there is not a participant in the transitivity of the clause.

In this study, in English texts, clauses that began with there were counted as existential clauses including unmarked new at the end of the clause. On the contrary, no existential theme was seen in Persian 
texts for two reasons: First, the existential theme does not have any correspondence in Persian. In Persian, an SOV language, There + be is squeezed in one compound verb and transposed to the end of the clause, leaving the subject position an optional place o be filled since Persian is a [+null subject] language. Second, as mentioned above, existential themes contain new information presented at the end of the clause functioning as rheme. This is true about English not Persian, and in translating into Persian, translators forefront the new information to comply with Persian canonical form. The nonexistence of existential themes in Persian does not necessarily bring more thematic cohesion in translated texts but account for a different thematic progression as different from the original text.

The extraposition theme, as another type of unmarked themes, was utilized rarely in English (21 cases 3.61 or \%) and it was nonexistent in Persian. McCabe (1999: 81) argues that the empty it, like the existential there, is not participant in the transitivity of the clause. Following Halliday (1994) and McCabe (1999), in cases of extraposition, only it was counted as theme here, while as mentioned before, some researchers such as Whittaker (1995) and Ghadessy (1999) take into account cases of extraposition as interpersonal theme. While in English an empty it is used in place of the extraposed subject, in Persian extraposed subject is used, and thus the subject may or may not appear initially. Note the following example:

(16) T-unit 2: $\underline{\boldsymbol{t}}$ does seem reasonable that physical gesture, involving the whole body, could have been a means of indicating a wide range of emotional states and emotions. Yule 1996: 3)

Translation: manteqi benazar miresad ke ijaade eshareee ke tavassote harkaate andaame su:rat migirad, kolle azaa badan ra shaamel shode. (Noormohammadi 2003: 3) (Reasonable seems that ....) 
While in English, it is only considered as theme of the clause, in Persian, the meaning of the phrase it does seem reasonable is considered as theme. It has no counterpart by itself in Persian and upon encountering such structures, translators forefront the accompanying noun or adjective following it. So, differences in frequency of some theme types might mark linguistic preferences and structural differences between English or Persian which translators are expected to be aware of so that they can pick out the right structure for translation that is both faithful in meaning to the original text and abides by Persian structure.

\subsection{Thematic progression}

The results of thematic progression showed that all patterns with the exception of split theme (linear, constant, and split rheme) were found in original and translated texts and chi-square revealed significant differences. As results showed, the proportion of linear patterns in Persian was greater. Though literature argues for its argumentative nature, the highly frequent use of linear patterns in translated texts may be one of Persian propensities. In Persian, a null subject language, the verb template is responsible for agreement and number, and so subject may or may not be realized overtly. Appearing in rheme position of the clause, a template, not the subject of the clause, forms a linear pattern due to its proximity when it conflates with the subject of the next clause.

Research has shown that academic texts present complex arguments in which an idea in the clause is expressed and explained in the successive clauses (McCabe 1999 \& Wang 2007). These arguments help the reader to be aware where the information has come from and where it is going, thus creating cohesion in the text. For this reason, an academic text requires to have a high frequency of linear links. McCabe (1999: 211) expresses that linear links set up relationships implying cause and effect, develop ideas, and improve 
cohesion between sentences in a paragraph. So, it can be concluded that one of the characteristics of argumentative texts is the use of high proportion of linear patterns. Besides, as argued in the present study, linearity also partly depends on linguistic features of a language.

In original texts constant patterns outrun linear patterns leading to simplistic, repetitive, and redundant paragraphs which may result from continuous application of the same topic. In Wang's point of view, constant patterns provide a more static text while in an argumentative text the "cross-referential" links from the rheme of one clause to the theme of the next clause can provide a more dynamic effect (2007). With constant patterns, as Wang (2007) states, the text often reads like a list and there is a lack of further expansion of information introduced in the rheme. In many existing academic texts, authors frequently make a list of factors on advantages or disadvantages, or factors contributing to or hindering a process with little or no further explanation to describe those factors. Therefore, this may lead to using constant progression patterns in creating more descriptive texts. In such cases, little argumentation is required as the writer is hooking the reader because he might not want to ensure readers' constant presence or optimally build up a conceptual scaffolding.

The final point to be stated here is about miscellaneous patterns. According to Wang (2007: 6), the overall effect of applying miscellaneous patterns is in creating text which is lacking in the development of ideas). Contrary to Wang's (2007) suggestion that miscellaneous chains distort the development of ideas, McCabe (1999: 180) argues that:

In no way are all of the themes in the corpus chained to a previous theme or rheme in close proximity. However, this does not necessarily mean that they are difficult to process, only that they are difficult to analyze in terms of linking 
them to one previous point in the discourse in order to say that they belong to one or another chain. These themes are important to the organization of the discourse; they are only labeled as peripheral in that they are peripheral to the thematic progression patterns.

Miscellaneous bonds are crucial to the development of the discourse and can provide thematic continuity in the text because of the accessibility of their references to the reader. Sometimes the reader goes back to more than three clauses to relate propositions together even though the clauses fall outside thematic rules because context compensates for the distance between the clauses by giving the reader the opportunity to rely on the contextual clues to link ideas together. And sometimes when a new idea that has no connection to the preceding clauses is introduced, analysis of thematicity requires great efforts on the part of the readers.

Generally speaking, translators should be aware of the important role of thematic progression in guiding the reader through the logical paths constructed by the writer. If little attention is paid in writing to this relationship, the reader may lose track of the context and get lost in a maze shaped by the translator.

Finally, the obtained findings attested to the fact that thematic structure is a greatly effective and valuable tool in translation. It lets translators be aware where they are losing their effectiveness in their arguments in terms of theme/rheme organization. It increases the relationship and connection between ideas in the text and so both writers and translators should have enough knowledge about thematic organization and progression in creation and interpretation of texts. Translators should get mastery over the grammar and structure of both source and target languages, particularly in terms of thematic structure since, as stated by Ventola (1995), in academic texts the theme/rheme patterns are important in guiding the reader through the logical paths constructed by the writer. If little attention is paid 
in translation to these rhetorical effects, the writer's attempts to help the reader are destroyed.

The findings of this study may be used in refining translation theory and practice, the issue which is the main motivation behind the present study. Attention to thematic organization and progression is an important issue in translation process. Texts vary thematically in different languages, and in order to translate better it is crucial that translators be conscious of the schematic patterns of both source and target languages. The awareness of theme/rheme structure can help translators interpret texts in three different modes: employing interpersonal themes, using topical themes, and applying textual themes. Through the first way, translators can establish the texts as exchanges between themselves and readers realizing the social relationships. By the second mode, translators are able to represent the patterns of experience, express propositional meaning, and make sense of what goes on outside and inside them. And, through the third mode, translators can organize the message in clauses, create texts, and establish a local environment in which readers can interpret their message.

Translators should be vigilant enough to mishandle no special pattern in the text, otherwise, they will violate the texture, and as a result the readers' response will be something different from what the writer intends to convey. Therefore, translators must be trained to be sensitive to converting information intended by original authors effectively and clearly into target language and creating cohesive text. The cohesion in texts can be improved if concentration is given to thematic organization and progression in texts. The connection between theme and rheme is a crucial point in creating a cohesive text. So, the knowledge gained from theme and rheme patterns are useful in translation process, and translators should pay attention to the relationship between sentences in a text or as Larson (1984: 261) puts it, between the propositions in order to translate into the receptor language. 
108 Thematic Development in English and Translated Academic Texts

The readers of original and translated texts also need to have sound knowledge about the way through which different thematic selections are realized. The awareness of this realization can guide them to follow writer's line of argument and help them to comprehend the texts better since the propositions realized by thematic options may vary depending on the purposes pursued by writers.

From pedagogical perspective, translators can apply the results of this study in translating English texts. The obtained results can help them in translation process in terms of appropriate theme selection, conveying the message more clearly as intended by the author, developing cohesion in discourse, creating a cohesive text, helping them to avoid the use of odd thematic structures that are not typical of the target language and make the text fuzzy, and helping readers to comprehend the text effectively.

\section{References}

Akmajian, A. et al. 1995. Linguistics: An Introduction to Language and Communication. Cambridge: The MIT Press.

Bahrami, A. 2003. Zabanshenasi: Daramadi bar zaban va ertebat. Tehran: Rahnama.

. 2005. Rooykardha va raveshha dar aamoozeshe zaban. Tehran: Rahnama.

Bloor, T. \& M. Bloor. 1995. The Functional Analysis of English: A Hallidayan Approach. London: Arnold.

Brown, H. 2000. Principles of Language Learning and Teaching. London: Longman.

Brown, G. \& G. Yule. 1983. Discourse Analysis. Cambridge: Cambridge University Press.

Chastain, K. 1988. Developing Second-Language Skills: Theory and Practice. San Diego, CA: Harcourt Brace Jovanovich.

Fahim, M. 2002. Osoole yadgiri va aamoozeshe zaban. Tehran: 
Rahnama.

Fahim, M. \& M. Haqqani. 2005. Osool va fonoone aamoozeshe zaban. Tehran: Rahnama.

Falk, J. 1978. Linguistics and Language: A Survey of Basic Concepts and Implications. New York: John Wiley \& Sons.

Freeman, D. 2000. Techniques and Principles in Language Teaching. Oxford: Oxford University Press.

Fries, P. 1995. Themes, Methods of Development, and Texts. In R. Hasan \& P. Fries (eds.), On Subject and Theme: A Discourse Functional Perspective 317-359. Amsterdam: John Benjamins.

Ghadessy, M. 1995. Thematic Development and Its Relationship to Registers and Genres. In M. Ghadessy (ed.), Thematic Development in English Texts 129-146. London: Pinter.

. 1999. Thematic Organization in Academic Article Abstracts.

Estudios Ingleses de la Universidad Complutense 7, 141-161.

Gomez, M. 1994. The Relevance of Theme in the Textual Organization of BBC News reports. World Journal 19(3), 293305.

Green, C. et al. 2000. The Incidence and Effects on the Coherence of Marked Theme in Interlanguage Texts: A Corpus Based Study. Journal of English for Specific Purposes 19, 99-113.

Halliday, M. 1985. An Introduction to Functional Grammar. London: Edward Arnold.

. 1994. An Introduction to Functional Grammar. London: Edward Arnold.

Halliday, M. \& R. Hassan. 1985. Language, Context, and Text: Aspect of Language in a Social Semiotic Perspective. Australia: Deakin University Press.

Matthiessen, C. \& M. Halliday. 1997. Systemic Functional Grammar: A First Step into the Theory. Retrieved 18 April 2007. Available at URL < http://minerva.ling.mq.edu.au >

Martinez, I. 2003. Aspects of Theme in the Method and Discussion Sections of Biology Journal Articles in English. Journal of 
110 Thematic Development in English and Translated Academic Texts

English for Academic Purpose 2, 103-123.

Matthiessen, C. 2004. Descriptive Motifs and Generalizations. In A. Caffarel et al. (eds.), Language Functional Perspective 537-673. Amsterdam: John Benjamins.

McCabe, A. 1999. Theme and Thematic Patterns in Spanish and English History Texts. Retrieved 9 July 2007. Available at URL $<\mathrm{http}$ //www. wagsoft.com/systemics/archive/McCabe.phd $>$

Munday, J. 2001. Introducing Translation Studies: Theories and Applications. London: Routledge.

Noormohammadi, M. 1999. Gostareshe maharat haye aamoozeshe zabane dovvom. Tehran: Rahnama

Noormohammadi, M. 2003. Barrasiye zaban. Tehran: Rahnama.

North, S. 2005. Disciplinary Variation in the Use of Theme in Undergraduate Essays. Journal of Applied Linguistics 26(3), 431-452.

Ping, A. 2003. Theme as Constructing Force. Journal of Language and Linguistics 2(2), 1-14.

Ravelli, J. 2004. Signaling the Organization of Written Texts: Hyper-Themes in Management and History Essays. In J. Ravelli \& R. Ellis (eds.), Analyzing Academic Writing: Contextualized Frameworks 104-130. London: Continuum.

Richards, J. \& T. Rodgers. 2001. Approaches and Methods in Language Teaching. Cambridge: Cambridge University Press.

Ventola, E. 1995. Thematic Development and Translation. In M. Ghadessy (ed.), Thematic Development in English Text 85-104. London: Pinter.

Wang, L. 2007. Theme and Rheme in the Thematic Organization of Text: Implication for Teaching Academic Writing. Asian EFL Journal 9(1), 1-11.

Whittaker, R. 1995. Theme, Process and the Relation of Meaning in Academic Articles. In M. Ghadessy (ed.), Thematic Development in English Text 105-128. London: Pinter.

Williams, I. 2005. Thematic Items Referring to Research and 
Researchers in the Discussion Section of Spanish Biomedical Articles and English-Spanish Translation. International Journal of Translation 51(2), 124-160.

Yule, G. 1996. The Study of Language. Cambridge: Cambridge University Press.

Zhou, Y. 2006. The Interpersonal Metafunction and Theme in English and Chinese Advertisement Texts. US-China Foreign Language 4(5), 46-50. 